\title{
THE IMPORTANCE OF STANDARDIZATION IN THE QUALITY OF A SCIENTIFIC PUBLICATION
}

The Journal of Venomous Animals and Toxins including Tropical Diseases has highquality format, not only in the presentation of its papers but also in its editorial policy on standardization. As requested by the Editor in chief, the application of this editorial policy is supported by the School of Library Science, UNESP, Marília, São Paulo, Brazil, which has two of its third-year students helping in the standardization of the journal's bibliographical references, supervised by Dr. Mariângela Spotti Lopes Fujita, professor of "Documentary Standardization". This partnership has been valuable for students' learning since it allows them to be in direct contact with a renowned international scientific journal. For the School of Library Science, UNESP, it means extension activity, since technical knowledge provided by the discipline can be employed and practiced.

Standardization in scientific journal is undoubtedly a pre-requisite for high-quality format, which influences text comprehension and scientific visibility. In a text, clarity is associated with a discreet and elegant standardization of its presentation, which highlights the merit of the subject. This situation can be clearly exemplified by the abstract, which has to express the idea of the whole paper as it is going to be read first. The role of citations is to provide theoretical and methodological bases for development of the work as well as to make the scientific paper more visible by the impact factor of highly cited publications. Presentation of methods and results by means of illustrations (photographs, drawings, graphs, tables and diagrams) clearly show the development and conclusion of the work. References of citations are found at the end of the paper. The overall view of the journal is obtained by the structure of the introductory elements, the text itself and the references displayed in a complete form according to standardization. All these format aspects are essential to the presentation of the contents and follow the rules set by Documentary Standardization.

The editor and the editorial board have established and do follow an editorial policy of standardization, demonstrating their concern about communication and scientific visibility of the originals published.

The responsibility of employing the techniques for article standardization must be shared between the editor and the professionals of the field of Library Science, whose knowledge of Information Management has accompanied the format evolution of scientific communication in different forms of documentary records - books, journals, academic papers, projects and reports, in printed or electronic media. In Library Science, documentary standardization comprises two phases: its production and treatment (descriptive and thematic), which is called documentary cycle and which has as its primary aim the organization of documents for future retrieval on databases and catalogs at libraries.

Standards for document preparation are proposed and elaborated by several groups and associations such as the International Standards Organization (ISO), the Brazilian Association of Technical Standards (Associação Brasileira de Normas Técnicas - ABNT), and the National Library of Medicine, a scientific group which adopts a standardization named Vancouver Style, elaborated by the 
INTERNATIONAL COMMITTEE OF MEDICAL JOURNAL EDITORS (ICMJE) from Vancouver, Canada, largely utilized by biological journals.

Standards are documented agreements containing technical specifications or other criteria to be constantly used as rules, instructions or definitions to assure that materials, products, processes and services be adapted for their purpose. To guide authors in the preparation of an article they intend to submit for review, there is a set of Standards from ISO and ABNT for specific aspects related to presentation, elaboration of abstracts and references, citations, etc, which are adopted according to each journal's editorial policy on standardization.

Following the acceptance of a paper, the editor starts to prepare the original for publication according to the standardization style adopted by the journal. The originals of The Journal of Venomous Animals and Toxins including Tropical Diseases are sent to students of the School of Library Sciences, who review documentary standardization aspects. During this work, they can consolidate knowledge obtained in the classroom, mainly when some doubts arise and are discussed and solved together with the professor of the discipline "Documentary Standardization". Many of these doubts have been studied and have contributed to the improvement of the course's syllabus, developing a knowledge sharing process among fields of diverse expertises.

Finally, as the professor of the discipline and on behalf of all the students of the School of Library Sciences, UNESP, Marília, I thank the opportunity this journal has offered us.

\section{CORRESPONDENCE TO:}

MARIÂNGELA SPOTTI LOPES FUJITA, Department of Information Science, College of Philosophy and Sciences, São Paulo State University, UNESP, Marília, SP, Brazil, Email: goldstar@flash.tv.br 